\title{
As NARRATIVAS DO MEDO E A CRIMINALIZAÇÃO DA JUVENTUDE: O DISCURSO PUNITIVO CONTRA ADOLESCENTES EM CONFLITO COM A LEI
}

\author{
Dione Antonio Carvalho de Souza Santibanez \\ Universidade Federal de Goiás (UFG), Goiânia, Goiás, Brasil \\ Najla Franco Frattari \\ Instituto Federal de Educação, Ciência e Tecnologia de Goiás (IFG), \\ Goiânia, Goiás, Brasil \\ DiJaCI DaVID OliveIRa \\ Universidade Federal de Goiás (UFG), Goiânia, Goiás, Brasil
}

Resumo: Neste artigo discutiremos sobre o tema da redução da maioridade penal. Para realizar o estudo tomaremos os dados sobre a participação de adolescentes em práticas criminais no Estado de Goiás nos anos de 2012 e 2013 . O objetivo é confrontar a participação concreta dos adolescentes com as narrativas sociais e proposições políticas em favor da redução da maioridade. A partir da leitura dos dados podemos observar uma forte discrepância entre as narrativas que apontam o potencial criminal dos adolescentes e os dados reais. A discussão resulta do diálogo articulado entre resultados de duas pesquisas: 1) Levantamento do Sistema Socioeducativo Municipal em Goiânia; e, 2) Violência Urbana no Estado de Goiás.

Palavras-chave: Maioridade penal. Adolescência. Criminalização da juventude. 
INTRODUÇÃO

O atual contexto de violência a que está submetida a juventude urbana no Brasil coincide com a propagação de um discurso que, em vez de compreendê-la como vítima, Ihe atribui a responsabilidade pela insegurança das grandes cidades. Predomina no senso comum a ideia de que o envolvimento de adolescentes e jovens com o consumo e tráfico de drogas é o fator determinante para o aumento da violência, em especial o homicídio. A partir dessa impressão mais geral e com suporte dos meios de comunicação de massa, o discurso repressivo ganha força e dissemina o anseio punitivo, reforçando o apelo por mudanças legislativas que levem ao endurecimento das leis penais. $O$ que atualmente se expressa no clamor pelo rebaixamento da idade penal. Os principais noticiários da grande mídia têm preferência por veicular fatos criminais em que há participação de adolescentes, insistentemente chamados de "menores". Além disso, faz questão de mencionar a necessidade de redução da maioridade penal ao noticiar casos de violência cuja autoria é de adolescentes.

Para discutir esse tema estruturamos este artigo em duas partes. Na primeira tentaremos analisar os dados sobre atos infracionais praticados por adolescentes. $O$ objetivo será confrontar o universo real dos dados criminais em comparação com a participação dos crimes cometidos por adolescentes. Compreendemos que a partir de tais confrontos será possível buscar respostas para os temores sociais quanto à participação deste segmento no universo criminal. Essas constatações resultam da análise parcial, de caráter quantitativo, dos dados coletados no projeto de pesquisa "Levantamento do Sistema Socioeducativo Municipal em Goiânia", realizado pelo Núcleo de Estudos sobre Criminalidade e Violência da Universidade Federal de Goiás. A pesquisa teve acesso aos prontuários da Secretaria Municipal de Assistência Social, aos registros mensais de ocorrências criminais da Delegacia de Apuração de Atos Infracionais e às estatísticas mensais e anuais da Secretaria de Segurança Pública e Justiça do Estado de Goiás.

Na segunda parte, a partir da pesquisa "Violência Urbana no Estado de Goiás", procuramos demonstrar como que os adolescentes são tomados como objeto de perigo e responsabilizados para além daquilo que fazem. Isto é, são transformados em "bode expiatório" de problema social da violência, da criminalidade e da sensação de insegurança. Mas não apenas isso, mas também de uma confluência de interesses sociais que precisam ser desvelados caso queiramos, de fato, compreender o que leva ao forte clamor social 
por mais punições aos adolescentes. A discussão sobre as percepções de medo e o anseio punitivo contra os mais jovens se dará a partir de uma análise qualitativa das falas de moradores de diferentes áreas da cidade de Goiânia. As entrevistas e grupos focais foram realizados entre os anos de 2012 e 2013. A pesquisa realizada teve 40 entrevistas semiestruturadas e nove grupos focais.

\section{VIOLÊNCIA, CRIMINALIDADE E ADOLESCÊNCIA}

Os dados quantitativos que indicam os atos infracionais praticados por adolescentes revelam uma realidade que coloca sob questionamento a visão comum de que os mais jovens são os principais autores de crimes violentos. A leitura dos indicadores das infrações cometidas deixa clara a disparidade entre as percepções sobre adolescentes e a real incidência de criminalidade que os envolvem. Ao contrário do que se pode observar em algumas falas, os crimes mais violentos são os menos praticados pelos adolescentes em conflito com a lei. Para isso, basta verificar ${ }^{1}$ que: i) a maioria dos crimes praticados em Goiânia não envolve pessoas com menos de 18 anos de idade; ii) a maioria dos atos infracionais praticados são contra patrimônio e não contra a vida.

Quadro 1 - Atos infracionais em Goiânia no ano de 2013.

\begin{tabular}{lr}
\hline Tipo & Porcentagem \\
Roubo & $19,7 \%$ \\
Dirigir sem CNH & $11,4 \%$ \\
Furto & $9,8 \%$ \\
Porte de drogas & $8 \%$ \\
Receptação & $6,8 \%$ \\
Tráfico de drogas & $6 \%$ \\
Tentativa de & $0,7 \%$ \\
Homicídio & $0,8 \%$ \\
Homicídio & $0,2 \%$ \\
Latrocínio & $36,4 \%$ \\
Outros & \\
\hline
\end{tabular}

Fonte: Projeto de Pesquisa Levantamento do Sistema Socioeducativo Municipal em Goiânia, 2014.

O Quadro 1 mostra que os atos infracionais que atentam contra o patrimônio (furto e roubo) correspondem a maioria: 36,3\%. Dirigir sem a Carteira Nacional de Habilitação é o segundo ato infracional mais praticado 
em Goiânia. O porte e tráfico de drogas, juntos, somam $14 \%$ dos casos. Já os crimes contra a vida (homicídio, tentativa de homicídio e latrocínio), mesmo somados, não passam de $1,7 \%$.

Essa realidade segue uma tendência nacional. No Brasil, os atos infracionais contra patrimônio representam a maioria das infrações praticadas por adolescentes (ver Quadro 2). Em 2002, roubo e furto correspondiam a $52,7 \%$ do total, enquanto os crimes contra a vida chegaram a $22,9 \%$. O tráfico de drogas correspondia a 7,5\%.

Quadro 2. Atos infracionais no Brasil em 2002.

\begin{tabular}{lr}
\hline Tipo & Porcentagem \\
Roubo e Furto & $52,7 \%$ \\
Tráfico de drogas & $7,5 \%$ \\
Lesão corporal & $2,2 \%$ \\
Homicídio & $12 \%$ \\
Latrocínio & $5,5 \%$ \\
Outros & $15,5 \%$ \\
Sem informação & $1,7 \%$ \\
Homicídio & $0,8 \%$ \\
Latrocínio & $0,2 \%$ \\
Outros & $36,4 \%$ \\
\hline
\end{tabular}

Fonte: Ipea/MJ-DCA. Mapeamento Nacional da Situação das Unidades de Execução de Medida de Privação de Liberdade (set-out/2002).

De acordo com o Mapeamento Nacional da Situação do Atendimento dos Adolescentes em Cumprimento de Medidas Socioeducativas, do Instituto Latino Americano das Nações Unidas para Prevenção do Delito e Tratamento de Delinquente (Ilanud), publicado em 2007, no ano de 2006, os atos infracionais contra patrimônio atingiram os $62,8 \%$, enquanto os crimes contra pessoa (vida) foram de 13,7\%. As infrações ligadas ao envolvimento com drogas somaram $16,1 \%$. Nota-se que houve um aumento no número de casos como roubo e furto (contra patrimônio) e o envolvimento com tráfico e consumo de drogas. Já os crimes como lesão corporal e homicídio (contra a vida) caíram. 
Quadro 3. Atos infracionais no Brasil em 2012.

\begin{tabular}{lr}
\hline Tipo & Porcentagem \\
Roubo & $38,7 \%$ \\
Tráfico de drogas & $27 \%$ \\
Homicídio & $9 \%$ \\
Furto & $4,2 \%$ \\
Lesão corporal & $0,8 \%$ \\
Outros & $20,3 \%$ \\
\hline
\end{tabular}

Fonte: Anuário Brasileiro de Segurança Pública, 2014.

Em 2012, o roubo e o furto apresentaram uma redução, caindo para 42,9\%; mantendo, apesar da queda, os crimes contra o patrimônio à frente dos demais índices. Os atos infracionais contra pessoa também caíram em relação aos períodos anteriores, destacando-se a diminuição da porcentagem referente à lesão corporal. Entretanto, a porcentagem de homicídios aumentou entre 2006 e 2012; registrando, entretanto, queda ao longo da década, de 12\% em 2002 para 9\% em 2012, mantendo-se entre os atos infracionais menos praticados. A mudança significativa está no aumento do tráfico, que saltou para $27 \%$. No geral, pode-se verificar que persiste a tendência de queda no percentual de atos infracionais violentos, que atentam à vida.

Dos casos de roubo registrados em Goiânia no ano de 2013, 97,5\% foi praticado por adultos. Considerando os homicídios registrados no município, no mesmo período, tem-se que $97 \%$ dos casos são pessoas com mais de 18 anos. Consequentemente, adolescentes são responsáveis por apenas $3 \%$ do total de homicídios que ocorreram na capital. Em Goiás, no ano de 2012, de acordo com o Anuário Brasileiro de Segurança Pública, a violência policial vitimou 80 pessoas de modo letal; o que corresponde a 3,3\% do total de homicídios registrados no estado. Enquanto que o número de homicídios praticados por adolescentes, no mesmo período, foi de 50; o que equivale a $2,1 \%$ do total. Dessa forma, os indicadores estatísticos demonstram que em Goiás, no ano de 2012, a polícia matou mais do que os adolescentes em conflito com a lei².

Esse tipo de comparação pode ser feito também ao considerarmos o cenário nacional. Do total de homicídios ocorridos em 2012, apenas 4,2\% foram de autoria de adolescentes. Neste mesmo ano, ainda de acordo com o Anuário, 1.963 pessoas foram vítimas fatais da ação de adolescentes e 2.332 foram mortas pela polícia. 
Se considerarmos que o Brasil tem mais de 20 milhões de adolescentes (12 a 17 anos completos, de acordo com o IBGE-Banco Sidra/Censo 2010); e pouco mais de 520 mil policiais, segundo o Anuário Brasileiro de Segurança Pública de 2013, podemos indagar o quanto a atividade policial tem sido violenta e proporcionalmente mais vitimizadora que adolescentes. Esses números indicam, aproximadamente, que brasileiros correm um risco 40 vezes maior de serem mortos por um policial do que por um adolescente $^{3}$. Contudo, as corporações policiais não aparecem nos discursos do medo propagados pela grande mídia e raramente são apresentados projetos de lei para ampliar o controle e a regulação das polícias. Diferente disso sobram propostas de lei para o endurecimento penal que afetariam diretamente a juventude.

Além disso, devemos destacar que os mais jovens são as maiores vítimas de homicídio no Brasil. De acordo com o Mapa da Violência 2014 (publicação prévia), de cada quatro jovens assassinados no país, três são negros e pobres; representam também estes, sete de cada 10 jovens mortos pelas polícias. A vitimização de jovens brancos, no período de 2002 a 2011, decresceu de $36,7 \%$ para $22,8 \%$ do total de homicídios; isso, enquanto a vitimização de jovens negros cresceu de $63 \%$ para $76,9 \%$. Além desses elevados índices de homicídios, a juventude negra e pobre é a mais atingida pelo nosso modelo de encarceramento. Atualmente, $38 \%{ }^{4}$ da população carcerária tem de 18 a 29 anos e 60\% é composta por negros. Assim, ao completar a maioridade, adolescentes em conflito com a lei podem ser público-alvo da política de encarceramento e/ou da violência policial.

A constatação de que as infrações contra patrimônio são maioria vai ao encontro do perfil socioeconômico de adolescentes em conflito com a lei. A partir da pesquisa "Levantamento do Sistema Socioeducativo Municipal em Goiânia", verificamos que $86 \%$ dos adolescentes que cumprem medida socioeducativa em meio aberto têm renda familiar de no máximo três salários-mínimos, destes, $24,7 \%$ estão excluídos de programas sociais. $70 \%$ estão em situação de evasão escolar e $95 \%$ não estão matriculados em curso profissionalizante. Trata-se, dessa maneira, do grande contingente juvenil que está marginalizado na capital de Goiás, considerada pela ONU-Habitat, em relatório de 2012, a cidade com maior concentração de renda da América Latina e a segunda mais desigual do mundo.

Nesta parte foi possível perceber, a partir dos dados concretos e coletados no município de Goiânia, que há uma forte discrepância entre os clamores da sociedade por mais punição contra adolescentes e sua real 
participação no universo criminal. Do total de crimes de roubo cometidos no município no ano de $2013,97,5 \%$ foi por adultos, contra menos de $3 \%$ cometidos por adolescentes. Da mesma forma, a ideia de que adolescentes estão cada vez mais violentos e agressivos é desmistificada pela desproporção observada, também, ao considerarmos os casos de homicídio, em que $97 \%$ são cometidos por adultos e apenas 3\% são de responsabilidade de adolescentes. Além disso, os dados mostram, ainda, um declínio, ao longo da década, de atos infracionais cometidos contra pessoa (homicídio, tentativa de homicídio e lesão corporal). Essa disparidade é que nos leva a questionar sobre como e porque os adolescentes acabam se tornando o foco preferencial do medo e do ódio da sociedade, como pode ser observado nas falas expressadas cotidianamente pelos moradores das grandes cidades. É o que pretendemos discutir na parte seguinte.

\section{AS REPRESENTAÇÕES DO MEDO E A AMEAÇA JUVENIL}

A sensação de insegurança e o sentimento de medo foram relatados pela maioria dos entrevistados em diversos espaços da cidade. Embora as experiências e percepções apresentem nuances diferenciadas dependendo do pertencimento socioeconômico dos entrevistados, as representações sobre o perigo revelam aspectos que são compartilhados pelos diferentes grupos. A articulação entre juventude e violência é um desses aspectos que permeia o discurso dos entrevistados pertencentes a diferentes estratos sociais, apresentando, por vários e diversos motivos, os jovens, especialmente os pobres, como produtores e protagonistas da violência urbana. Adolescentes, por sua vez, são colocados como símbolo de ameaça e medo nas narrativas de moradores de bairros de classe alta e média, bem como nos bairros populares de Goiânia.

Eh... Crianças, assim, adolescentes que a gente vê que estão na rua. Porque eles fazem qualquer coisa por causa de um dinheirinho, podendo até matar. Então, são esses grupinhos de adolescentes e de rapazes é que me põem medo. O setor, como toda cidade, a gente ouve dizer e vê pela televisão muitos assaltos. A rua aqui não está muito boa não. Com o Parque Vaca Brava [parque localizado no Setor Bueno - área nobre da cidade] aqui próximo, nos finais de semana foi tomado por jovens. A praça foi tomada por eles, virou um ponto de drogas, e amanhece aqui tudo tomado de cacos de garrafa. Rapazes e moças que vem da periferia para uso de maconha e outras coisas piores aqui no bosque. O Shopping é aqui pertinho, mas eu não vou a pé de 
jeito nenhum. Essa moçadinha é perigosa! Você vê que hoje quem tá praticando a maioria dos crimes é eles. Que criança nada! São frios e perigosos! (Morador de bairro classe alta).

Se de um lado os moradores dos bairros populares se sentem ameaçados pela presença do tráfico e de toda violência que essa atividade traz para as localidades onde se instala, de outro, os moradores dos bairros de classe média e alta, como o Setor Bueno, afirmam se sentirem expostos e vulneráveis à vitimização por acreditam que são alvos atrativos e rentáveis para os criminosos, que almejariam os bens de alto valor que esses possuem. Na percepção desses entrevistados, "os marginais" vêm de outros bairros da cidade para praticar crimes no setor, uma vez que sabem que as pessoas que ali residem possuem alto poder aquisitivo e podem oferecer maiores benefícios materiais aos agressores. $O$ crime e os criminosos estão associados a determinados espaços que supostamente lhes dão origem. Em muitas falas os espaços considerados perigosos e violentos são os bairros periféricos da cidade. Uma ideia bastante recorrente nas entrevistas realizadas com os moradores do Bueno, e também de outros bairros onde reside a elite econômica da cidade, consiste na percepção de que a periferia seria a responsável por "fornecer" os assaltantes, marginais, delinquentes, que agiriam no bairro, em função da visibilidade social que as pessoas desse lugar têm.

As pessoas que moram aqui não são violentas. Quem vem assaltar aqui é realmente gente de fora, desses bairros distantes. Eles vêm pra cá porque aqui chama muito a atenção. É um bairro que as pessoas têm mais dinheiro, têm mais bens, estão mais expostas. $O$ fato de aqui ter um poder aquisitivo maior atrai os bandidos pra cá, pra ficar perto de nós. Aí, você tem esses medos, de sair na rua, de sair à noite. O pobre tem muito filho, a classe média vai ter cada vez menos. (Morador de bairro classe alta).

Os entrevistados dizem se sentirem ameaçados, principalmente, por acreditarem que as ações dos criminosos, no intuito de obter esses bens, são cada vez mais violentas e, muitas vezes, podem ter desfechos trágicos. $\mathrm{Na}$ percepção dos entrevistados os criminosos não compartilham dos mesmos valores morais que "as pessoas de bem", são audaciosos e não se importam de matar ou ferir para conseguirem o que querem. Por serem jovens, em sua maioria, os criminosos são tidos como afobados, não medem as consequências de seus atos e gostam de demonstrar poder, o que aumenta o medo e a insegurança. 
Os marginais, eles não têm valor moral. Essa coisa que a gente tem de gostar das pessoas, amar as pessoas, os entes queridos da gente, tanto faz para eles, então, eu temo mais por isso mesmo, risco de morte. Eles são todos jovens. Você pode observar. Muitos menores de idade. Não têm qualquer pudor em matar para conseguir tomar uma carteira.

Na maioria das narrativas dos membros da elite, os jovens, especialmente os jovens pobres, constituem personagens centrais da violência urbana e principal alvo das demandas por medidas cada vez mais repressivas. No caso específico dos adolescentes, a vinculação entre pobreza e criminalidade parece ser ainda mais presente e significativa. Concebidos como indivíduos incompletos, em formação, eles seriam mais suscetíveis aos efeitos do meio social (família, comunidade, a rua). De modo que os bairros pobres e as periferias da cidade tendem a ser identificados como territórios marginais e perigosos, de onde advém o crime e onde proliferam os criminosos. Esses espaços são aqueles sobre os quais recaem prioritariamente as demandas dos entrevistados por uma atuação rigorosa e impiedosa da polícia, principalmente com relação aos jovens.

Em geral, esses territórios são percebidos de forma homogênea como espaços de ilegalidade e sem regras. Embora a violência tenha grande expressão nesses espaços e os moradores dessas áreas pobres e com escassos recursos sejam os mais expostos à morte violenta, eles têm sido apontados de forma generalizada como os responsáveis pelo aumento da criminalidade, com ênfase especial para os jovens e adolescentes ali residentes.

Assim como para os moradores do Setor Bueno e de outros bairros de classe média e alta de Goiânia, para a maioria dos entrevistados residentes nos bairros populares, como Vila Mutirão e Jardim Curitiba, o medo é uma constante. $O$ principal motivo apresentado para esse sentimento é o aumento da criminalidade e da violência na vizinhança nos últimos tempos, em função da difusão do tráfico de drogas. Viver nesses bairros nos dias atuais é viver com medo, o que se contrapõe a um tempo anterior onde, segundo os entrevistados, era possível desfrutar das ruas e calçadas para conversas aprazíveis com os vizinhos no final da tarde e deixar as crianças correrem livres pelas ruas.

De acordo com as narrativas, homicídios, roubos e furtos à residência, roubo ao comércio, e roubo a transeuntes são bastante comuns nesses setores. A violência nesses espaços é experimentada de modo bastante concreto e "rotineiro" pelos moradores que dizem que viram a vítima, ouviram os tiros, ouviram gritos e discussões. Os jovens moradores dessas localidades são apresentados nas falas como os principais agentes da violência e criminalidade 
presentes nesses bairros, além de serem apontados como responsáveis pela sensação de medo e insegurança.

Não é novidade alguém morrer, alguém ser assaltado. Eu tenho medo sim. Nessa rua aqui têm três bocas de fumo, uma delas é controlada por um menino de 13 anos. Os viciados tem dia que eles dormem aí na rua. Todos jovens, bem novinhos. Eu tenho medo deles. As pessoas que moram aqui já esperam "o pior" todos os dias quando sai de casa. (Morador de bairro popular).

A pesquisa revelou ainda que não é somente nos discursos dos membros da elite que o clamor por mais repressão e até mesmo a defesa do extermínio, especialmente em relação à juventude, ganha força. Nos bairros populares pesquisados, muitos dos jovens assassinados eram conhecidos dos vizinhos e tiveram suas trajetórias acompanhadas por eles. Os casos de homicídios envolvendo esses jovens com ligação com o tráfico de drogas não causam grande comoção entre a maioria dos moradores, que afirmam que essas mortes são mais ou menos "esperadas e certas". A associação ao tráfico de drogas faz com que a vítima se torne culpada e única responsável pelo seu destino. Todavia, o que mais amedronta os moradores é a possibilidade de que toda essa violência atinja pessoas que não têm qualquer tipo de participação ou envolvimento com o tráfico.

Falou que morreu muita gente, muito jovem, mas se você for ver a maioria mexia com o tráfico. $O$ que mais acontece aqui são acertos de conta. A pessoa morre porque está envolvida com alguma coisa. A questão da violência, quando eu ouço falar que alguém matou, no geral, a única coisa que eu pergunto é se era "mala". Então, a gente pensa assim, enquanto está morrendo "mala", está bom. É até um alívio! Porque eles atormentam a nossa vida aqui! É um inferno essa molecada. Eles são perigosos! São bandidos mesmo! Não duvide! A gente alerta para isso (violência) quando está prejudicando pessoas inocentes. Eu mesmo tenho medo de ser confundido com alguém ou de tomar uma bala perdida. (Morador de bairro popular).

Este cenário que coloca os jovens pobres como protagonistas da violência e criminalidade urbanas parece justificar a reivindicação dos entrevistados por diminuição da maioridade penal, e de outro lado, "legitimar" uma situação alarmante na qual adolescentes e crianças são brutalmente exterminados por policiais e oponentes nas periferias das grandes cidades brasileiras. 
Quando a questão é violência e criminalidade urbana, os discursos, de um modo geral, acabam quase sempre ressaltando a necessidade de punição rigorosa com relação aos atos ilícitos praticados por menores. As falas enfocam muito a questão da responsabilidade imputada ao jovem aos 16 anos, uma vez que este é considerado apto a exercer a cidadania por meio do voto e que, consequentemente, deve ser passível de punição legal caso se envolva na prática criminal. Muitas narrativas enfocam a comodidade da prática delituosa por adolescentes em função do conhecimento da não imputabilidade penal que lhes é garantida por lei. Todavia, a resposta a esse contexto de vulnerabilidade e insegurança tem sido a defesa de medidas duras, onde se discute, inclusive, a implantação da redução da maioridade penal e da pena de morte. A desestruturação das forças coercitivas (a Justiça e a Polícia) é relatada como um ponto fundamental para explicar a crescente ação dos criminosos. Em contrapartida, exigem-se instituições que punam com rigor e uma polícia que prenda bandidos, que atue com vigor, mesmo que isso contrarie garantias constitucionais e direitos civis.

A partir dos 14 anos as pessoas têm que ser presas, porque hoje em dia os meninos da $8^{\text {a }}$ série estão vendendo para os meninos menores. Tem muito menorzinho matando, roubando, não é só aqui na Região Noroeste, em qualquer lugar, mas aqui é maior. Tem muito ladrãozinho, esses menininhos metido a ser "mala". Todo mundo sabe que estão armados, sabe que está usando, vendendo e estão por aí dizendo: "vou fazer e não posso ser preso e quando eu for maior de idade eles vão limpar a minha ficha". Já sabe que não pode fazer e faz. Então faz porque gosta, tem gente que mata porque quer matar, têm uns que roubam porque querem roubar. (Moradora de bairro popular).

Esses discursos encontram ressonância e vão de encontro aos dados apresentados pela pesquisa "Violência Urbana no Estado de Goiás"s, que buscou captar o sentimento de insegurança dos moradores da cidade de Goiânia, bem como seus comportamentos, hábitos e valores em face do medo da violência. A pesquisa realizada por professores e alunos da Universidade Federal de Goiás, no ano de 2008, e que teve como um de seus objetivos a realização de um survey sobre vitimização e sentimento de insegurança entre diferentes grupos sociais na cidade, entrevistou 2.000 moradores e revelou uma quase unanimidade em relação à redução da maioridade penal, entendida como medida fundamental para redução da violência, não havendo diferenciações significativas para os indivíduos pertencentes a diferentes grupos sociais. Os 
moradores dos bairros populares apresentam inclusive, uma porcentagem um pouco maior de aprovação da medida em relação aos segmentos médios e a elite goianiense, sendo que $87,8 \%$ destes concordaram com a necessidade da aprovação da lei. Ao lado de um pouco mais de $80 \%$ dos moradores dos bairros de classe média e alta.

A intolerância tem sido, portanto, uma reação bastante comum em cenários de medo crescente, onde as pessoas tendem a aceitar e defender qualquer medida capaz de mitigar ao menos no seu imaginário a sensação de insegurança que assola os cidadãos. As representações sobre a ineficiência do sistema de justiça penal em julgar e punir exemplarmente os criminosos justifica, muitas vezes, a procura por estratégias individuais de autoproteção baseadas na crença de que os indivíduos só podem contar com eles mesmos para assegurar a sua proteção em face dos perigos e ameaças que rondam a vida cotidiana da cidade. Tornam-se evidentes, portanto, os efeitos desestruturadores do medo, haja vista os inúmeros impactos negativos que são impostos aos diversos grupos sociais.

A tendência de endurecimento penal parece tornar-se evidente no caso dos adolescentes, seja pela defesa da redução da maioridade penal, seja pelos constantes ataques ao Estatuto da Criança e adolescente, visto como mais uma lei para "defender bandidos", "aprendizes de marginal". Ganha espaço na mídia e entre a população de um modo geral a representação de uma juventude sem limites, irrecuperável, perigosa e que, portanto, deve sofrer uma punição exemplar. Em contraposição à ideia de proteção e recuperação dessas crianças e adolescentes, sobrepõem-se as exigências de punições penais. A exigência de rigor penal e as punições são tidas por muitos entrevistados como uma forma de "exemplo" para a sociedade, uma forma de demonstrar que "as coisas não correm soltas". Essa visão pungente na sociedade atual não abandona a correlação pobreza e criminalidade, sendo o adolescente pobre apontado como um dos protagonistas principais da maioria das cenas de violência e criminalidade encenadas nas cidades brasileiras.

Nesse contexto, podemos afirmar que os jovens se tornaram objeto ostensivo dos discursos políticos no Brasil, nos últimos anos. Isso não significa exatamente que eles ganharam importância como sujeitos de direitos, mas, contrariamente, que seus direitos, em especial, aqueles estabelecidos no Estatuto da Criança e do Adolescente (ECA), têm sido fortemente questionados. Isto é, os jovens são apontados como um problema para o bem-estar social e uma ameaça contra a vida do cidadão comum. Esses problemas têm sido fartamente destacados por diversos parlamentares brasileiros desde o início 
dos anos de 1990 (DOMINGOS, 1993; LOBO, 1996; RODOLFO, 1999; FRAGA, 2001; ARRUDA, 2001; REZENDE, 2002; COSTA, 2003;TORRES, 2007) e, diante do cenário de violência, propõem a modificação de algumas leis do ordenamento jurídico nacional que permitam ampliar a punição deste segmento social.

Como resultado da interpretação dos parlamentares é que tramitam tanto na Câmara dos Deputados quanto no Senado Federal mais de 60 propostas que objetivam a redução da maioridade penal ${ }^{6}$. De acordo com os defensores das propostas, a violência está "descontrolada" e, diante de tal situação, um dos caminhos apontado pelos legisladores está na modificação do artigo 228 da Constituição Federal do Brasil'.

Se analisarmos mais atentamente, a partir das propostas dos deputados e senadores, podemos concluir que, também para eles, os adolescentes são os responsáveis pela maior parte da violência cotidiana, que as regras de maioridade penal vigentes representariam um obstáculo para a garantia de segurança e que, a redução da maioridade penal permitiria uma diminuição da violência. Isto é, assumem plenamente os "clamores populares" por mais punição contra adolescentes. Em favor dos parlamentares pesa o apoio ostensivo da mídia, em particular, os programas televisivos dedicados aos noticiários policiais e à chamada "imprensa marrom" (ANGRIMANI, 1995) e mesmo a chamada imprensa tradicional (OLIVEIRA, 2013). A partir da cobertura sistemática dos crimes se construiu um cenário de aterradora violência, de cultura do medo e, finalmente, de medo dos jovens.

Com uma leitura dos projetos de emenda e projetos de lei apresentados pelos representantes políticos podemos observar um espectro amplo de razões para justificar a redução da maioridade penal. Algumas proposições se destacam: a) a diferenciação entre idade biológica e idade mental; b) afirmação de as gerações atuais serem mais informadas; $c$ ) de que os adolescentes são usados para cometer crimes; d) de que temos uma ineficiência do sistema socioeducativo, e enfim; e) que os jovens estão envolvidos em crimes mais bárbaros.

Para responder às premissas propostas pelos parlamentares devemos desenvolver várias outras questões. Entre elas poderíamos questionar se, de fato, há uma desconexão entre idade biológica e idade mental. Os jovens estão se tornando adultos mais cedo? O fato de que possam adquirir mais conhecimento os tornam socialmente mais responsáveis? As gerações atuais são mais informadas? Quais são as representações que a sociedade possui dos jovens? 
Essas questões, evidentemente, não esgotam o espectro de dúvidas que poderíamos levantar. Todavia, sem respostas para essas e outras questões, uma tomada de decisão sobre a redução da maioridade penal se apresenta precária e prematura. Os cenários reais não são exatamente como demonstram os parlamentares.

Se os jovens de hoje estão "conectados e mais informados", por outro lado temos os dados da Pesquisa Nacional por Amostra de Domicílios (Pnad) de 2009 que põe em xeque essa premissa ao apontar que o índice de analfabetismo funcional da população brasileira atinge 20,3\% (IBGE, 2009). Consideremos ainda que "os analfabetos funcionais não possuem habilidades de leitura, escrita e cálculo para fazer face às necessidades da vida social e profissional dos nossos tempos" (MOREIRA et al. 2004, p.16). Desse modo, se a capacidade de acessar ou receber e compreender uma informação é um pressuposto para a capacidade de discernimento, então temos um problema muito maior pela frente.

Evidentemente que as ideias de jovem nas propostas dos parlamentares não estão "desconectadas" da realidade, mas fazem parte de uma realidade de interesses. Lá estão os jovens consumidores de classe média e alta, assim como estão os jovens pobres e sem capacidade de consumo. Quando o legislador propõe a redução da maioridade penal, ele está olhando para esses jovens. Assim como se tem dezenas de propostas de redução da maioridade penal para criminalizar jovens (SOUZA; CAMPOS, 2007), existe outra dezena disposta a modificar o mesmo dispositivo (artigo 228) constitucional para assegurar que jovens de 16 e 17 anos possam dirigir (OLIVEIRA, 2009).

\section{CONCLUSÃo}

A maneira como esse discurso punitivo tem afetado a sociedade brasileira coloca a juventude como uma condição que aproxima as pessoas dos riscos ligados à criminalidade e violência. Sob essa população recai o estigma da "bandidagem", carregando a culpa do perigo iminente, da possibilidade de ocorrências criminais, da insegurança constante e das incivilidades persistentes. Eleger os mais jovens como inimigos públicos possibilita colocá-los num lugar estratégico para a reprodução das desigualdades. Ao enxergá-los como pequenos bandidos, desprovidos da condição de sujeitos de direitos, sendo ainda movido pelo desejo de maior punição, tornamos esse grupo social invisível para os investimentos públicos (educação, saúde, equipamentos urbanos, saneamento, etc.). Ao mesmo tempo, fazemos deles visíveis para 
as políticas de controle e punição (policiamento, judicialização e encarceramento). Agora, não apenas no campo do discurso, como também no campo político-econômico, a juventude deixa de ser socialmente projetada como o futuro, para representar o perigo.

Decorre-se, desse quadro apresentado, a tendência de que haja uma substituição de políticas de inclusão social por mecanismos de controle e punição cada vez mais repressivos. No campo discursivo, a condição social da juventude da classe trabalhadora, no lugar de público-alvo dos projetos integradores da política econômica do país, passa a ser percebida como grupo social sob constante suspeita, devendo se submeter a mecanismos investigação, monitoramento e judicialização mais intensivos; o que permitiria a algumas instituições estatais agir de maneira a suspender direitos fundamentais.

Na mídia, por exemplo, o enfrentamento às drogas é encarado como questão de defesa nacional, consubstanciado na expressão "guerra ao tráfico". Isso, por sua vez, limita o entendimento de que o consumo de substâncias prejudiciais ao organismo pode ser visto como questão de saúde pública, que exige investimento em programas de prevenção e conscientização, envolvendo instituições educacionais, assistenciais e de defesa de direitos.

É preciso considerar que esse deslocamento na percepção social que temos dos mais jovens é uma tendência, defendida por um discurso específico e que, por hora, não atingiu as políticas estatais na sua totalidade. Vivemos o período histórico do Brasil de maior fomento aos programas e projetos de inclusão social de jovens, da distribuição de renda ao acesso a serviços públicos essenciais, como o ensino superior e formação técnica para o trabalho. Todas essas conquistas e seu desenvolvimento, porém estão ameaçadas pelo discurso que criminaliza a juventude; isso. por colocá-la como protagonista da criminalidade no lugar de protagonista social.

Artigo recebido em: 14/11/2014 Aprovado para publicação em: 16/12/2014

THE NARRATIVES OF FEAR AND YOUTH CRIMINALIZATION: PUNITIVE DISCOURSE AGAINST YOUTH OFFENDERS

ABSTRACT: This article discusses the reduction of the minimum age of criminal responsibility. To conduct this study, we analyzed the data about adolescent participation 
in criminal activities in the State of Goiás in the years 2012 and 2013. The goal was to confront the adolescents' concrete participation in such crimes with the social narratives and the political propositions in favor of lowering the minimum age of criminal responsibility. By interpreting the data, we realized a strong discrepancy between the narratives that links the criminal potential of teenagers and the real data. The discussion results from the dialogue articulated between the results of two surveys: 1) Survey of the Municipal Socio-educational System in Goiânia; and, 2) Urban Violence in the State of Goiás.

KeYwords: Criminal Responsibility Age. Adolescence. Criminalization of youth.

\section{LAS NARRATIVAS DEL MIEDO Y LA CRIMINALIZACIÓN DE LA JUVENTUD: EL DISCURSO PUNITIVO CONTRA ADOLESCENTES EN CONFLICTO CON LA LEY}

RESUMEN: En este artículo vamos a discutir sobre el tema de la reducción de la edad penal. Para el estudio tomaremos los datos sobre la participación de los adolescentes en prácticas criminales en el Estado de Goiás en los años 2012 y 2013. El objetivo es hacer frente a la participación concreta de los adolescentes con las narrativas sociales y proposiciones políticas en favor de la reducción de la edad penal. A partir de la lectura de los datos se puede observar una fuerte discrepancia entre los relatos que vinculan el potencial criminal de los adolescentes y los datos reales. La discusión de los resultados articula el diálogo entre los resultados de dos investigaciones: 1) Búsqueda del Sistema Municipal Socioeducativo en Goiânia; y, 2) La violencia urbana en el Estado de Goiás.

Palavras clave: Edad legal. Adolescencia. Criminalización de la juventud.

\section{NOTAS}

1) Fonte: Projeto de Pesquisa Levantamento do Sistema Socioeducativo Municipal com dados levantados junto à Secretaria de Segurança Pública e Delegacia de Apuração de Atos Infracionais. As porcentagens resultaram de cruzamentos estatísticos a partir de duas bases diferentes, fornecidas pelas instituições; são elas: “Estatística Mensal/Consulta Procedimento" e "Relatório Estatístico de Ocorrências de Alta Prioridade", ambos de 2013. Já os dados referentes aos homicídios praticados por policiais têm por fonte o "Anuário Brasileiro de Segurança Pública", publicado em 2014, com dados de 2012 e 2013.

2) A Secretaria de Segurança Pública do Estado de Goiás não divulga os dados de homicídio cuja autoria é de agentes das corporações policiais. Por isso, tivemos que 
restringir as informações sobre a letalidade policial ao relatório do Fórum Brasileiro de Segurança Pública.

3) Valor estimado com base em cálculo de razão de chance, a partir de teste Qui-quadrado (x2), através da análise de tabela de contingência ( $2 \times 2)$, usando método não paramétrico.

4) Fonte: BRASIL. Ministério da Justiça. Departamento Penitenciário Nacional - Sistema Integrado de Informação Penitenciária (Infopen). Brasília, 2011.

5) A pesquisa "Violência Urbana" no Estado de Goiás foi coordenada pela professora Dalva Maria Borges de Lima Dias de Souza, do Programa de Pós-Graduação em Ciências Sociais, da Universidade Federal de Goiás. O projeto contou com financiamento da FINEP (Financiadora de Estudos e Projetos). A pesquisa planejada para ser realizada em diversas etapas, com o uso de diferentes metodologias, teve como um de seus objetivos a realização de um survey sobre vitimização e sentimento de insegurança em 13 municípios goianos, incluindo a capital, Goiânia. Os resultados da pesquisa estão publicados no livro "Violência Urbana em Goiás: Práticas e representações" (2011).

6) De acordo com Oliveira (2009), de 1972 a 2009 foram apresentadas 63 propostas na Câmara e no Senado Federal. Destas, 49 na Câmara e 14 no Senado.

7) $O$ referido artigo define a idade penal aos 18 anos, assegurando às crianças e aos adolescentes um tratamento diferenciado para sua punição, bem como a inimputabilidade para menores de 12 anos. Para os parlamentares que objetivam a redução, isso se torna necessário, uma vez que se observa uma maior participação dos jovens na criminalidade (OLIVEIRA, 2013).

\section{REFERÊNCIAS}

ANGRIMANI SOBRINHO, Danilo. Espreme que sai sangue: um estudo do sensacionalismo na imprensa. São Paulo: Summus, 1995.

ARRUDA, José Roberto. Proposta de Emenda Constitucional (PEC) n. 3, de 22 de março de 2011. Brasília: Senado Federal, 2001.

BORGES, Doriam. O medo do crime na cidade do Rio de Janeiro: uma análise sob a perspectiva das crenças de perigo. Curitiba: Appris, 2011.

BRASIL. Ministério da Justiça. Departamento Penitenciário Nacional - Sistema Integrado de Informação Penitenciária (Infopen). Brasília, 2011.

COSTA, Wladimir. Proposta de Emenda Constitucional (PEC) n. 179, de 8 de outubro de 2003. Brasília: Câmara dos Deputados, 2003. 
DOMINGOS, Benedito. Proposta de Emenda Constitucional (PEC) n. 171, de 26 de outubro de 1993. Brasília: Câmara dos Deputados, 1993.

FRAGA, Alberto. Proposta de Emenda Constitucional (PEC) n. 321, de 10/2/2001. Brasília: Câmara dos Deputados, 2001.

IBGE - Instituto Brasileiro de Geografia e Estatística. Pesquisa Nacional por Amostras de Domicílios (Pnad) - Síntese dos Indicadores Sociais. IBGE: Brasília, 2009.

IPEA/MJ-DCA. Mapeamento Nacional da Situação das Unidades de Execução de Medida de Privação de Liberdade (set-out/2002). Brasília, 2003.

ILANUD, ONU. Mapeamento Nacional da Situação do Atendimento dos Adolescentes em Cumprimento de Medidas Socioeducativas. Brasília, 2007.

Ipea, 2012.

. Sistema de Indicadores de Percepção Social (SIPS) - Segurança. Brasília:

LOBO, Nair Xavier. Proposta de Emenda Constitucional (PEC) n. 426, de 6/11/1996. Brasília: Câmara dos Deputados, 1996.

MACHADO DA SILVA, Luís Antônio. Sociabilidade violenta: Uma dificuldade a mais para a ação Coletiva nas Favelas. In: Rio: a democracia vista de baixo. Rio de Janeiro: IBASE, 2004.

MOREIRA, D.; MOREIRA, P.; CANO, C.; MYCZKOWSKI, M. Analfabetismo funcional: conceito, medidas e efeito sobre a produtividade e eficácia. Cadernos de Pós-graduação. São Paulo, v. 3, n. 2, p. 17-29, 2004.

OLIVEIRA, Antonia Maria de Fátima. Documento de habilitação para menores de dezoito anos. Brasília: Câmara dos Deputados, 2009.

OLIVEIRA, Dijaci David de. Quem ganha com a criminalização do jovem no Brasil? In: SILVA, Denival Francisco da; BIZZOTTO, Alexandre (Org.). Sistema punitivo: custos e lucros, qual a dimensão da criminalidade? Goiânia: Kelps, 2013.

REZENDE, Iris. Proposta de Emenda Constitucional (PEC) n. 26, de 22/5/2002. Brasília: Senado Federal, 2002.

RODOLFO, Nelo. PEC n. 169 altera o artigo 228 da Constituição Federal, para tornar penalmente inimputáveis os menores de quatorze anos. Brasília: Câmara dos Deputados, 1999.

SOARES, Glaucio A. D. Não Matarás: desenvolvimento, desigualdade e homicídios. Rio de Janeiro: Editora da Fundação Getúlio Vargas, 2008.

SOUZA. Luís Antônio Francisco de; CAMPOS, Marcelo da Silveira. Redução da Maioridade Penal: uma Análise dos Projetos que tramitam na Câmara dos Deputados. Revista Ultima Ratio, Rio de Janeiro, ano 1, n. 1, p. 231-259, 2007. 
TORRES, Demóstenes. Parecer sobre as propostas de emenda à constituição n. $18 \mathrm{e}$ 20, de 1999; 3, de 2001; 26, de 2002; 90, de 2003; e 9, de 2004, que alteram o art. 288 da Constituição Federal para reduzir a maioridade penal. Brasília: Senado Federal, 2007.

WAISELFISZ, Júlio Jacobo. Mapa da violência 2012. A cor dos homicídios no Brasil. Brasília. Instituto Sangari; Ministério da Justiça, 2012.

. Mapa da violência 2013. Mortes matadas por armas de fogo. Brasília. Instituto Sangari; Ministério da Justiça, 2013.

. Mapa da violência 2014. Os jovens do Brasil. Brasília. Instituto Sangari: Ministério da Justiça, 2014.

Dione Antonio Carvalho de Souza Santibanez: Doutorando em Sociologia pela Universidade Federal de Goiás e Professor Substituto da Faculdade de Ciências Sociais da UFG. É coordenador do Núcleo de Estudos sobre Criminalidade e Violência.

E-mail: dioneantonio@smail.com

NaJla Franco Frattari: Doutora em Sociologia pela Universidade de Brasília e Professora do Instituto Federal de Goiás. Pesquisadora do Núcleo de Estudos sobre Criminalidade, Violência e Justiça Criminal da Universidade Federal de Goiás. Tem experiência na área de Sociologia, com ênfase em Sociologia Urbana, atuando principalmente no seguinte tema: violência, segregação socioespacial, sentimento de insegurança.

E-mail: najlafrattari@smail.com

DiJaCl David OliveIRA: Doutor em Sociologia pela Universidade de Brasília. Diretor da Faculdade de Ciências Sociais da Universidade Federal de Goiás. Atua nas seguintes linhas de pesquisa: direitos humanos, diferença e violência; violência noticiada.

E-mail: dijaci@gmail.com 